\title{
Historia de la Anatomía en Chile Parte II. El Alma Mater
}

\author{
History of Anatomy in Chile Part II. The Alma Mater
}

Julio Cárdenas Valenzuela

\begin{abstract}
CÁRDENAS, V. J. Historia de la Anatomía en Chile Parte II. El alma mater. Int. J. Morphol., 38(4):1074-1089, 2020.
RESUMEN: Los conocimientos anatómicos luego de impartirse en los primeros 200 años de nuestra historia de manera extrauniversitaria, pasan a enseñar en 1978 desde la Real Universidad de San Felipe, al Instituto Nacional en 1833 y de éste, a la actual Universidad de Chile, en 1842. Siguiendo los preceptos de las Primas de Medicina españolas, el desarrollo de la disciplina se realizaba en condiciones deplorables, llenas de riesgos asociados a infecciones y heridas durante las prácticas, haciendo mención al origen de los primeros cadáveres utilizados para la docencia, en un periodo que va entre el año de 1842 cuando nace la Universidad, y 1920, año en que el Instituto de Anatomía se traslada a su actual ubicación, periodo en el cual son franceses los primeros profesores, recibiendo posteriormente influencia alemana, para luego recibir el influjo norteamericano. Este trabajo describe la continuación de la enseñanza de la Anatomía Humana, dependiente de la institución más antigua en fucionamiento del país, la Universidad de Chile, origen y alma mater de muchos anatomistas, quienes desarrollaron la enseñanza de la anatomía en el resto del país.
\end{abstract}

PALABRAS ClAVE: Anatomía; Historia de la Anatomía; Universidad de Chile.

\section{INTRODUCCIÓN}

Como se ha señalado en los inicios de la disciplina de anatomía humana (Cárdenas, 2017),y en sus comienzos extrauniversitarios, la enseñanza de la medicina se realizaba según la usanza española, siguiendo las indicaciones de la Pragmática, cátedra prima de Medicina (Rabí, 2006) donde todos los contenidos eran desarrollados por un profesor tal como se hacía en otros países de nuestra américa y con muy escasos recursos, con un comienzo muy lento y entorpecido por la falta de profesores con formación adecuada. De hecho, solo después de 200 años de la llegada de los españoles se funda la primera universidad en Chile supeditada inicialmente a la Universidad de San marcos de Lima, donde debían terminar sus estudios los estudiantes de la Universidad de San Felipe, impartiéndose los estudios médicos en latín, idioma docto circunscrito al ámbito universitario. Anatomía en cambio se daba fuera de los ámbitos universitarios, en idioma romancista, local, con clara menor importancia, usándose libros antiguos y desactualizados, fundamentalmente españoles y franceses (Silva, 2019).

Solamente en la segunda escuela de medicina de 1833 y dependiente formalmente del Instituto Nacional, la enseñanza de la anatomía se da como parte de las aulas universitarias, elevando su carácter y siendo impartida ahora por profesores dedicados a ello. Poco interés demostrado por los estudios médicos, y más bien distraídos por el derecho y las leyes, los postulantes eran escasos en estas artes en sus comienzos, lo que paulatinamente va cambiando en el tiempo, estimulados por becas y no pocas veces por obligaciones que incluso ministros, señalaban a sus hijos.

Este trabajo intenta por tanto, señalar la continuacion de la enseñanza de la disciplina de Anatomía Humana, ahora dependiente de la Universidad de Chile, la institución de nivel superior más antigua en funcionamiento actualmente en el país.

\section{La Anatomía en la República Conservadora (1831-1861)} continuación.

\section{La Universidad de Chile}

Con la promulgación del decreto que creaba la Universidad de Chile el 19 de noviembre de 1842, la Escuela de Medicina del Instituto Nacional quedó incorporada a la Escuela de Medicina de esta Universidad. De acuerdo a la Ley Orgánica de la propia Universidad, ésta no tenía un carácter docente, sino más bien debía encargarse de diversas tareas destinadas al progreso del país y a su desarrollo cultural. 
Debería esperarse hasta el establecimiento del estatuto universitario de 1879 para que la Universidad volviese a tener un carácter docente. Los planes de estudio se renovaban periódicamente, creciendo aceleradamente el número de médicos y por espacio de un siglo desde 1850 , la medicina chilena recibiría la influencia además de la francesa, de la medicina alemana. En 1852 se lleva a cabo una nueva reforma a la educación en Chile, y desde ese entonces la instrucción secundaria o preparatoria queda destinada al Instituto Nacional y los de la instrucción universitaria o profesional y científica a la Universidad.

A Morán le sucede el francés Julio Francisco Lafargue, quién gana el concurso en ausencia de su contendor, el Dr. Polar ante una comisión nombrada por el Gobierno compuesta por el Rector del Instituto Nacional, el presidente del protomedicato, don Agustín Nataniel Miers Cox, y los profesores Guillermo Blest y Lorenzo Sazié. Lafargue, es brillante en sus exposiciones, hábil disector, de vastos conocimientos, de una notable cultura literaria, premiado en varias oportunidades en Francia. Según se dice, se habría expatriado de Francia cuando, en 1840, regresando a Burdeos, teatro de sus triunfos académicos, se presenta a un concurso de cirujanía, y a pesar del informe de la comisión que lo declaraba el más acreedor, este destino habría sido dado a otro. Se presenta a la ceremonia de "picar puntos" (acto en que se señala con un puntero la parte del libro sobre la que debía versar el examen). Le toca hablar sobre el Bazo, su anatomía y fisiología efectuando una verdadera historia comparada sobre este órgano (Semir, 1860). Es designado profesor por decreto el 7 de Mayo de 1841.

Las condiciones de estudio siguen siendo tan paupérrimas como antes, debiendo los alumnos asear incluso las salas y trasladar los cadáveres en salas mal ventiladas, sin agua ni paños con que secarse, sin ni siquiera tener vestuario adecuado para ello.

Viendo esto Lafargue, solicita un mozo tanto para efectuar el aseo como para el traslado de cadáveres, muebles e instrumentos, los que le son otorgados por el gobierno de la época. Presenta un nuevo plan de estudios y reglamenta la enseñanza de la Anatomía, revelando los últimos avances en esplacnología y descripciones medulares y cerebrales, practicando las primeras inyecciones en venas y arterias; pasaba en su sala de trabajos siempre solo, leyendo sus libros, efectuando sus trabajos en medio de sus disecciones ejecutadas con una asombrosa habilidad, dignas de un anfiteatro europeo, pero con los exiguos recursos locales. A sus disecciones unía disertaciones sobre el área disecada. Tal eran las cualidades de su docencia, que los alumnos de cursos anteriores, personas ajenas a los estudios médicos y facultativos ya formados acudían nuevamente al año siguiente a escucharlo. Introdujo como texto el Manual del Anatomista, del francés Ernesto Alejandro Lauth (18031837). Es el iniciador de los trabajos anatómicos en Chile, de hecho fue el primero en realizar disecciones de angiología. Era, según Orrego Luco, un viejecito triste de una fisonomía delicada y melancólica, que tenía una expresión doliente, de ojos claros, cabeza fina y un pliegue de amargura contraída en sus labios.

Renuncia a la cátedra en 1843 y permanece como secretario de Escuela hasta 1845, época en que se fue al Perú debido a unos artículos aparecidos en una revista de Valparaíso donde se señalaba que había ratificado un informe dado por el Dr. Carlos Buston, francés también, sobre el origen de una mano izquierda hallada en la calle Estado por un camión recolector de basura. Mal atribuida a una mujer, no era sino una mano de un puma, hecho aclarado posteriormente por un propietario de un fundo cercano a Santiago apellidado Bustamante, quién señaló haber dado muerte a una leona en su fundo, habiéndole regalado su mano a uno de sus criados negros quién come su carne, para luego botar el resto a la basura, dónde posteriormente le encuentran. $\mathrm{Su}$ error: haber afirmado aquello sin revisar la muestra (Ferrer, 1904).

Es hallado muerto el 10 de Agosto de 1850 con una herida en la región crural, luego que aquel problema recibido en los primeros años de su carrera científica en Chile afectara su honor, problema que se acrecienta al enterarse de la quiebra del banco francés en que tenía depositado sus ahorros; "Su muerte no fue el efecto de las dolencias físicas que la ciencia que profesamos tiene por objeto hacer desaparecer. Pocedió de afcciones morales, más agudas a veces que las dolencias físicas, verdaderas enfermedades del alma, en cuyos misterios ha podido penetrar poco la observación i la ciencia", referencia de J. Aguirre sobre la muerte de su profesor Lafargue. (Anales U. de Chile, 1850).

En 1853 habían sólo 17 alumnos en toda la Escuela. Cada curso contaba sus víctimas en la mitad, por trabajar sobre cadáveres cuyas causas de muerte a veces eran infecciosas desconocidas, o bien, producto de la descomposición de sus cuerpos. En el primer curso de Morán en 1833, de 3 alumnos murieron 2 en el tercer año; en el segundo curso, de 6 alumnos murieron otros 2; en el tercero, de 5 murió 1 , y en el cuarto, murió otro (Semir), lo que mejora sólo desde 1853 cuando se nombra a un disector para efectuar los trabajos anatómicos, que hasta ese instante se realizaban por el profesor con ayuda de los alumnos, lo que disminuye ostensiblemente la tasa de mortalidad de los alumnos.

Según decreto del 8 de junio de 1850: "Se renovará en cada año, y será elegido entre los alumnos más adelan- 
tados, a propuesta del rector". Firma el Pdte. Bulnes y su ministro Antonio Varas.

En esos años, las clases aumentan de 3 a 5 a la semana, una diaria, por ello la necesidad de contar con un disector.

"Los trabajos prácticos constituían el horror de los estudiantes, se efectuaban a pleno sol en verano o en la humedad y en el barro en invierno, sin más instrumentos que una navaja catalana, un martillo y un serrucho sobre los cadáveres ya putrefactos, expuestos a la interperie por varios días, y que por escasos había que utilizarlos por completo, sin asepsia ni antisepsia, hasta entonces desconocidas, todo contribuyó a hacer insoportable los trabajos anatómicos y quirúrgicos convirtiendo en sacrificados a los pobres estudiantes.” Dr. Miguel Semir, año 1860, discurso de incorporación a la Facultad de Medicina, en referencia a este periodo.

Recordemos que Martín Avello había sido el primer alumno fallecido documentado a causas de las prácticas anatómicas en que las condiciones eran muy precarias, con nulos elementos de prevención ante este tipo de prácticas.

El origen de los cadáveres para la práctica anatómica en la Escuela de Medicina tenía en ese entonces 4 fuentes, que a veces significaba en los primeros tiempos, de un desembolso pecuniario (Ferrer):

a)“Los ejecutados", como el que es solicitado por Lorenzo Sazie (Flores, 1933).

b) "Los recién operados", cuerpos pertenecientes a pacientes fallecidos de accidentes anestésicos o quirúrgicos, habitualmente del hospital San Vicente de Paul por su cercanía.

c) "Los cadáveres de la morgue" cuerpos de personas jovenes fallecidos en peleas, habitualmente del matadero por heridas cortopunzantes. Eran los mejores según relatos de la época: habitualmente se dejaban para disección de musculatura.

d) "Los cadáveres de las infecciones crónicas", mal aseados, desnutridos, pertenecian a pacientes fallecidos en los hospitales con tuberculosis. Otros, con insuficiencia hepática, renal y cardiaca, llegaban edematosos, habitualmente desaseados y con parásitos. Cárdenas \& Mora, 2018)

La anterior reforma de 1847 del Instituto Nacional se había hecho deficiente debido a los progresos de los estudios científicos, y los cursos se daban además cada tres años, por lo que se alejaban las postulaciones de los alumnos que sin embargo aumentaban en interés. A eso había que señalar la escasez de profesores, por lo que se agrega en 1860 un curso adicional de Anatomía, dictándose en primer año la Descriptiva, en segundo las disecciones y en tercer año la Anatomía de regiones, esto es, Topográfica. En virtud del nuevo plan de estudios de ese año, la cátedra ahora es exclusivamente anatómica, separándose de fisiología, y no dependía tampoco de cirugía como antes, siendo ahora ejercida por un Profesor (como se menciona en el decreto del 4 de julio 1860). Aumentarían a 6 los profesores y la carrera duraría 6 años abriéndose ahora los cursos cada 2 años. Existiría un Director para dirigir y ejercitar a los estudiantes de los 2 primeros años en las disecciones y cuidados del gabinete y colecciones. Desde 1860 por decreto de Abril, el nombramiento de los disectores dejó de ser anual, dándoles mayor importancia y jerarquía en la Escuela.

A Lafargue, le sucede Victor Nicolás Pretôt en 1845 en forma interina; abogado y médico, nace en Namur, ciudad belga cuando ésta se encontraba bajo la dominación francesa. Se hace cargo del curso durante un año y medio, pero lo abandona antes de terminarlo, se casa con la hija del pdte. Ramón Freire y fallece posteriormente en Valparaíso el 16 de septiembre de 1867 (Vega, 1904).

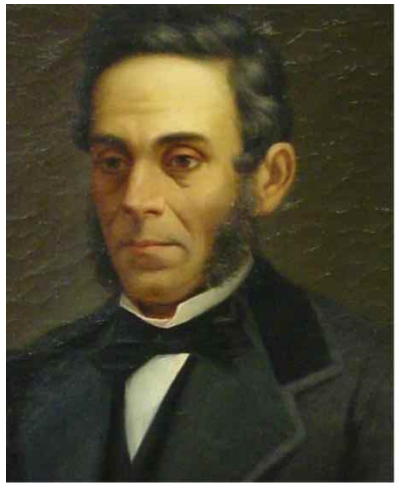

Vicente Padín

(1815-1868)

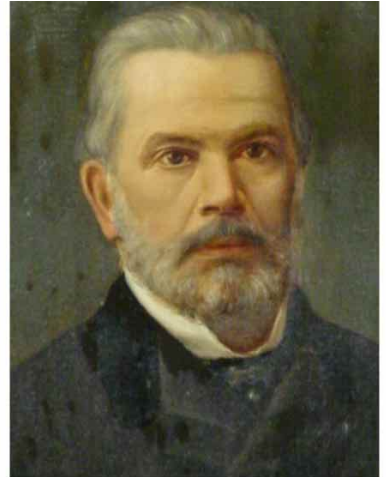

José Joaquín Aguirre

(1822-1901)

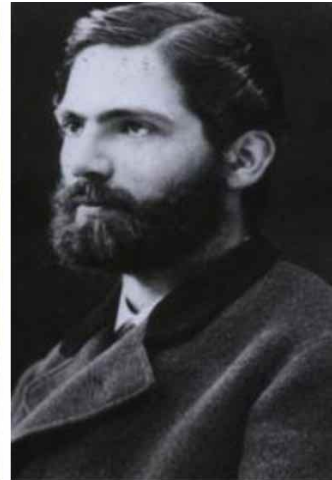

Augusto Orrego Luco

(1849-1933)
La anatomía en la República Liberal (1861-1891)

A Pretôt le reemplaza el licenciado Vicente Padín (Fig. 1). Nacido en Valparaíso, era de pequeña estatura con un aire enfermizo, muy cuidadoso de su traje, de modales discretos. Discípulo de Morán ocupa el cargo en oposición a Francisco Javier Tocornal,

Fig. 1. Profesores Drs. Vicente Padín (18151868), José Joaquín Aguirre (1822-1901) y Augusto Orrego Luco (1849-1933). 
hijo del Ministro del Interior. El tema versó "sobre los nervios craneales y las ramas del V y VII y funciones de la generación”. No siendo buen disector, su acción se limitaba generalmente a dar y tomar lección, logrando presentar a los alumnos en 6 meses al examen final. Utilizaba al igual que Lafargue, el texto de Lauth. El 26 de febrero de 1861, a Padín se le designa profesor de fisiología y medicina legal, por lo que es nombrado como profesor de anatomía José Joaquín Aguirre. Padín fue decano de la Facultad de Medicina en 1863 por 3 años. Inicia en Chile la prensa médica con carácter exclusivamente científica, funda "El Médico Práctico", cuyo director sería el Dr. Pablo Zorrilla. Fallecería el 28 de abril de 1868.

José Joaquín Aguirre (Fig. 1) nace en Los Andes un día 22 de Mayo de 1822. En su docencia le acompaña ahora un disector, obtenido antes por Padín, y solicitado previamente por Lafargue. De esta manera, el disector podía dedicarse ahora a preparar por si mismo el cadáver en sus demostraciones y así el profesor de la Cátedra no desatendería la instrucción teórica de los estudiantes, dando un mayor énfasis al trabajo práctico y a las disecciones, haciendo trabajar ahora a los alumnos de los dos primeros años que hasta ese entonces no hacían sino mirar:

"Vamos a estudiar la Anatomía, decía J.J. Aguirre, el cadáver será nuestro maestro; los libros nuestro guía, y yo los ayudaré en el estudio" (Orrego, 1924).

Fue pionero en colocar en el estudio de la Anatomía descriptiva el estudio de la Histología; cambia el libro introducido por Lafargue (Manual de disección de Lauth) por el de Jamain, francés, cambiando el giro de la enseñanza, solicitando que los alumnos presentasen sus preparaciones haciendo más práctica la anatomía. En 1866, se le designa profesor interino de Cirugía, para lo cual poseía condiciones excepcionales. Publica en 1865 en forma anónima El Manual de Anatomía General e Histología General, el primero impreso en América del Sur sobre la materia. Fue diputado por los Andes y por Santiago, y es elegido Decano en 1867, siendo luego elegido por otro periodo, llegando a la Rectoría de la Universidad posteriormente el año 1889. La escuela tenía 40 alumnos.

Decisiva fue en 1874 la visión del decano José Joaquín Aguirre, anatomista y cirujano, de enviar becados a Europa a jóvenes médicos destacados, iniciativa que se convertiría en política de las facultades de medicina chilenas, algo que se repetiría en otros países jóvenes de nuestra América. Entre otros, estudiaron David Benavente anatomía en Alemania; Vicente Izquierdo, histología en Alemania; Teodoro Muhm, fisiología en Alemania; Adeodato García Valenzuela, química en Alemania; Daniel García
Guerrero, medicina interna en Francia y Alemania; Manuel Barros Borgoño, cirugía en Francia; Lucas Sierra, cirugía en Francia; Francisco Puelma Tupper y Aureliano Oyarzún, anatomía patológica en Alemania; Máximo Cienfuegos, oftalmología en Alemania. En la segunda mitad del siglo comenzó a cobrar importancia la influencia alemana, apareciendo en esa época los primeros textos escritos por médicos chilenos. Los alumnos aumentan llegaron a 187 en 1875.

En 1876 se suprime la obligatoriedad del latín en la enseñanza liceana y con ello decayó su importancia para los médicos. Contra esta medida se manifestó el decano José Joaquín Aguirre. Durante la guerra con Perú y Bolivia forma parte de una Comisión Sanitaria teniendo gran participación en la organización de las ambulancias y hospitales provisorios. Fallece en Cartagena, en el mes de enero de 1901, y en su memoria, la escuela inauguró el Instituto de Anatomía en el centenario de su nacimiento, el 22 de Mayo de 1922.

En 1863 los Drs. Valderrama, Díaz, Murillo y Zorrilla recién egresados, se presentan a concurso para la cátedra de Anatomía Quirúrgica y Patología Externa; la comisión propone a Valderrama, que fue nombrado el 6 de Julio de 1863 a la edad de 29 años.

Se inaugura en el año 1863 el edificio reconstruido de la Escuela de Medicina en la calle San Francisco en la cuadra del Hospital San Juan de Dios se pintan y restauran las dependencias interiores; había 5 profesores, 10 cátedras y 40 alumnos. Ahí se trasladaron las clases teóricas que hasta entonces se habían hecho en el Instituto Nacional. La práctica clínica ya se realizaba en aquel Hospital. Los planes de estudio se renovaron periódicamente, mientras el número de profesores, cátedras y alumnos seguía creciendo en forma constante pero lentamente.

La motivación por estudiar medicina era baja según el profesor Semir, debido a dos causas:

$1^{\circ} \mathrm{A}$ la predilección de los caballeros por los estudios legales y forenses (sic).

$2^{\circ} \mathrm{A}$ la carencia de comodidades para el estudio y los útiles necesarios para ello.

Según los relatos del Dr. Augusto Orrego Luco en "Recuerdos de la Escuela", la Escuela de Medicina era un pequeño edificio, diseñada por el arquitecto don Manuel Aldunate, (cuyos planos eran de 1861). Sólo tenía el pórtico acorde a su importancia, con una gran puerta central (según algunos, para poder pasar el carretón que llevaba los cadáveres al interior) a cuyos lados había 2 grandes ventanas con hermosas rejas. Todo el frontis era estucado, sobre 
su pórtico un bajo relieve tamaño natural que representa una lección de Anatomía, cuyo autor era un tal Plaza. Al interior, existía un zaguán central, ancho y corto; se había trasladado en 1857 el anfiteatro de anatomía que se componía de dos salas construidas muy posteriormente al resto del edificio, de cal y ladrillo a ambos lados, altas, de piso entablado y cielo de madera, con paredes pintadas al temple, y molduras en sus ventanas y puertas; la de la izquierda tenía una gran estantería en un costado, donde se guardaban grandes bocales con alcohol en cuyo interior existían preparaciones y objetos anatómicos destinados a la docencia; anteriormente esa sala era ocupada en el edificio antiguo como gabinete por el Dr. Lafargue.

En 1865, señala Orrego Luco en "Recuerdos de la Escuela", que el Gobierno adquiere en 1.000 pesos, (Boletín de las Leyes y de las Órdenes y Decretos del Gobierno, 1846) en Europa la estatua anatómica del Dr. Ansoux (sic), la que es ubicada en esta sala, figura en cartón piedra de tamaño natural, con piezas desmontables que dejaban ver debajo de él al órgano que se había levantado. Sin embargo agrega el Dr. Enrique Laval, que esta estatua habría llegado en 1846 al país en forma accidental y "por ser en su género una de las obras más perfectas que pueden presentarse en Europa, según resulta del examen que han hecho de ella personas inteligentes", y "que ofrece al mismo tiempo, grandes ventajas a la facilidad y perfección de los estudios anatómicos", un Decreto Supremo del 26 de Diciembre de ese año, autoriza al director del Museo Nacional para adquirirla. En 1864 llegaría a anatomía. Lo cierto es que luego aparece en dependencias de anatomía (Laval, 1964).

\section{Estatua anatómica}

\section{Santiago, Diciembre 26 de 1846}

181 Con lo expuesto por el Director del Museo Nacional $i$ por el Decano de la Facultad de ciencias Médicas de la Universidad, $i$ considerando:

1. Q Que la estatua anatómica del Doctor Anssoux, recientemente llegada a esta Capital, es en su jénero una de las obras mas perfectas que pueden presentarse en Europa, según resulta del exámen que han hecho de ella personas inteligentes:

$2^{\circ}$ Que esta pieza venida accidentalmente a Chile es uno de los objetos mas preciosos que pueden figurar en el gabinete de historia natural i que ofrece al mismo tiempo grandes ventajas a la facilidad i perfeccion delos estudios anatómicos:

$3^{\circ}$ Que su importante adquisición se ofrece al Gobierno por un precio que los inteligentes consideran moderado;

He acordado i decreto:
El Director del Museo Nacional procederá a Comprar para ese establecimiento la estatua anatómica del Doctor Anssoux en la cantidad de mil pesos, que los ministros de la tesoreria general le entregarán al efecto, deduciéndola de la partida destinada a gastos imprevistos en el presupuesto del Ministerio de Instruccion Pública.

Refréndese, tómese razon i comuníquese.

$$
\begin{array}{cc}
\text { Bulnes José Manuel Borgoño } \\
\text { Boletín de las Leyes, págs, 357-358 }
\end{array}
$$

Después de más de 140 años y olvidada en el tiempo y sin ninguna referencia desde entonces, el autor encontraría esta estatua en dependencias del subterráneo de Morfología. Deteriorada sin ninguna mantención, es posible apreciar aún los nombres en francés que cada estructura tiene adosada, con ganchitos de bronce para su sujeción, constituyendo pues, la pieza anatómica de uso docente más antigua del país; otras piezas de papel maché llegarían al país en 1874, tambien de autoría de Louis .T. J. Auzoux (Chanal, 2014). Mayor descripción de la misma y antecedentes es posible evidenciar en un trabajo anterior de Cárdenas (2015).

Al otro lado del zaguán existía otra sala similar a la anterior, donde se impartían las clases teóricas de Patología, Fisiología, Medicina Legal y otras. En una pared había un banco delante del cual existía una larga mesa, con un sillón de paja en uno de sus extremos. Estas dos piezas fueron construidas en 1863.

Atrás, existía un edificio antiguo de dos piezas pequeñas también, alrededor de un pequeño patio. Una de las piezas era del portero, la otra, angosta, larga y de techo baja, de género blanqueado, tenía el piso de ladrillo, con una puerta y una ventana. En su interior tenía un estante y una silla pintados de negro, con varias sillas alrededor, servía como sala de estar de los profesores, y a veces como lugar para tomar exámenes. Cerrando ese patio existían otras dos piezas, una sala estrecha con una claraboya servía al profesor y al disector, además de una mesa cubierta de mármol, un armario para instrumentos y unos cuantos bancos transportables. Para los alumnos, una sala similar, más obscura, sin claraboya; para disecar, debían salir al exterior en una mediagua cubierta por zinc, al frío en invierno, debiéndose parar sobre ladrillos para no estar sobre suelo húmedo. Estas eran las piezas que en 1833 fueron inauguradas por Morán a las que hace alusión el profesor Semir : "En el primer patio del Hospital San Juan de Dios había en el fondo un cuarto común, con una mesa para las disecciones y un armario para los instrumentos, pomposamente le llamaban "el Anfiteatro anatómico". 
Atrás de esta construcción, un gran patio con un galpón que servía de pesebrera a las mulas y de refugio al "carretón de los muertos", medio de transporte de cadáveres desde los hospitales hasta una gran barraca ubicada al lado. "Ese carretón de los muertos le daba la nota original y extraña a toda la vida de la antigua población. En las altas horas de la noche, ese carretón atravesaba la ciudad con un ruido sordo, peculiar, inconfundible. Desde muchas cuadras de distancia se sentían los golpes secos, lúgubres, desiguales de ese enorme carretón cerrado, que resonaba como una gran caja sonora. Todo el vecindario conocía el ruido de ese carretón, todos sentían en la noche el ruido de esa marcha fúnebre"(Orrego).

Años más tarde, relata el profesor Orrego Luco, todo el frontis de la escuela fue modificado, se borró el arco de entrada, se eliminó el frontispicio y se rellenaron las ventanas de la entrada agregándose un segundo piso a la construcción. En ese entonces la Escuela de Medicina era una dependencia de la Universidad que funcionaba en el patio grande del Instituto Nacional, que da a la calle Arturo Prat, y que se llamaba "el patio Domeyko". Serían los últimos años de esa escuela, estaría naciendo ya la necesidad de construir una nueva.

Al tomar J. J. Aguirre la cátedra de Cirugía, en 1866, le sucede en Anatomía, el Dr. Pablo Zorrilla, gran disector; a él se le atribuye la formación del Museo de Anatomía, continuado luego por Ambrosio Coste. Zorrilla continua con el trabajo anatómico de J. J. Aguirre, no efectuando innovación en la enseñanza. Es director del gabinete de Anatomía, llamado más tarde Museo, en la Escuela ubicada aún en la calle San Francisco, en dependencias construidas especialmente para ello como se señaló desde 1857. Diez años más tarde existían alrededor de 176 piezas de las más importantes 56 eran de anatomía patológica según lo que señalaba Orrego Luco. Fueron también disectores Valderrama, Murillo y Domingo Gutiérrez.

En 1868 a petición de los profesores se modificó nuevamente el plan de estudios, se obligó a asistir a los hospitales a los alumnos; en el primer año se dictaba anatomía descriptiva, en el segundo, anatomía topográfica y las disecciones. La Facultad de medicina contaba con una matrícula de 78 alumnos y 9 profesores. Se produjeron otras reformas en la enseñanza, aumentando el número de alumnos haciéndose por ello insuficiente el espacio, por lo que además, se inició una cátedra paralela de anatomía descriptiva a cargo de Valentín Saldías en 1870; brillante médico, muy prestigioso, y humilde, nació en 1826 en Santiago, no ambicioso a pesar de su fama, rechazóa en varias oportunidades el decanato de la Facultad, siendo el primer médico del hospital Salvador, fue delegado del protomedicato de
Talca donde ejerció, ajeno a los honores y el dinero, modesto y austero, gran clínico, alumno predilecto de Sazié, fue además diputado por Santiago; muere el 19 de diciembre de 1887.

En 1872 se pusieron las primeras piedras del Hospital San Vicente de Paul y del Salvador. El primero, que estaba en el costado sur de la Escuela, se convertiría en hospital clínico universitario y por ello, tendría comunicación con las dependencias de la Escuela de Medicina, por ende, con anatomía. El hospital se destruiría con el incendio que afectó a la Escuela en 1948. En 1873, el Dr. Ramón Allende Padín señaló en carta dirigida a J. J. Aguirre conocer algunas preparaciones de Coste que demostraban la circulación arterial y venosa, la distribución de los nervios y otras de notable mérito. Pensó erróneamente que luego de 6 años estarían estas piezas perfectamente organizadas, sin embargo, se percató que estaban en completo abandono, a pesar de estar en una magnífica sala de los patios universitarios, con buena luz y extensión suficiente.

Cuando Saldías pasa a Fisiología en 1872, Augusto Orrego Luco (Fig. 1), le reemplaza; nace en Valparaíso el 2 de mayo de 1848, prosector de Aguirre en 1871 y 1872, fue nombrado profesor de Anatomía en 1874. Alternó sus estudios médicos con sus aficiones literarias, adquiriendo los disectores con él una categoría mayor, tomando el título de Jefe de Trabajos (31 de Mayo de 1888). Realizó sus clases con la preparación anatómica preparada por el disector, y exigió a los alumnos treinta preparaciones. Participó en la Guerra con Perú y Bolivia, siendo comandante de las fuerzas cívicas de la ciudad de Santiago. Posteriormente organizó brillantemente los servicios médicos en conjunto con los alumnos en la epidemia de viruela de 1872 un año antes de obtener su título profesional, y la epidemia de viruela de 1892, además de epidemia de viruela de Valparaíso en 1905, haciéndole merecedor en dos oportunidades de la medalla de oro. Publicó entre otras obras "Sepultados vivos" en 1876 (Vaisse, 1961). Santiago en 1875 tenía 120.047 habitantes.

En 1877 se emitió el decreto que permitía a las mujeres el ingreso a la universidad. Los prosectores ahora deben revisar al menos 30 preparaciones de disección de los alumnos, quienes al menos debían dedicar 9 horas semanales para ello, extendiéndoles una papeleta como recibo; sin éstas, no podían rendir examen. $\mathrm{Al}$ año siguiente se acuerda que en el tercer año se enseñará Anatomía Topográfica por el ayudante de medicina operatoria. Se establece ese año la dictación anual de los cursos.

En el año de 1879 estaba a punto de estallar la Guerra del Pacífico y el 6 de abril, a un día de haberse declarado la Guerra el Gobierno de Chile hace un llamado los jóvenes 
de la patria para defender los intereses de nuestra nación. Treinta días antes, el 6 de marzo los alumnos y académicos de la Escuela de Medicina habían hecho público en el anfiteatro de la escuela su intención de salir en defensa del país:

"era menester acudir en auxilio del hermano herido caído en defensa de nuestra hermosa bandera; marchemos pues a su lado y mientras las bayonetas defienden a la Patria defendamos nosotros ese ejército de sus enemigos naturales y contrarrestemos la naturaleza en su beneficio, $Y$ por fin, si fuera necesario tomemos el fusil y empuñemos la espada en defensa de la patria."

Presidida por el Decano Wenceslao Díaz, la Comisión estaba integrada por los Dres. Miquel, Allende Padín, Aguirre, Murillo, Hidalgo, Schneider, Orrego Luco, entre otros profesores y los alumnos de medicina Pedro Regalado Videla, J.M. Salamanca, F. Gutiérrez, E. Lillo entre otros, "para que arbitre y ofrezca al gobierno y a nuestro valiente ejercito los auxilios y sacrificios de nuestra profesión" (CruzCoke, 1995).

Uno de ellos, Pedro Regalado Segundo Videla Órdenes siendo interno no dudó en enrolarse en la Armada y, apenas terminadas sus prácticas hospitalarias, expresa: "Me voy de cirujano a la Marina y voy satisfecho y orgulloso, acabo de recibir de mi padre permiso para morir por mi querido Chile". Era un joven que, a comienzos de 1871, rindió sus exámenes para titularse de bachiller en Filosofía y Humanidades en la Universidad de Chile ingresando ese año a la Escuela de Medicina. Finaliza sus estudios en marzo de 1879, alcanzando el título de Licenciado en Medicina con una tesis que trataba sobre "La Rabia", tema muy poco conocido en la época. Destinado como primer cirujano a la goleta "Covadonga" pequeño buque de 400 toneladas, sirvió inicialmente a las órdenes del capitán de fragata Arturo Prat Chacón, quien fuera reemplazado por el comandante Carlos Condell cuando Prat se hiciera cargo de la corbeta Esmeralda el 16 de mayo de 1879.

A primera hora del 21 de mayo de 1879, Pedro Videla se hallaba en cubierta de la Covadonga, viendo el acercamiento de los buques enemigos y las primeras disposiciones tomadas por el comandante Prat. A las 9 de la mañana, y mientras bajaba al entrepuente donde se había instalado la enfermería en combate, ayudado por el contramaestre Serapio Vargas y el mozo de la cámara Felipe Ojeda, un proyectil de 300 libras de cañón del "Huáscar" atravesó la goleta de banda a banda, llevándose de paso los pies del cirujano Videla y matando al joven Felipe Ojeda. La herida que le produjo el proyectil al doctor Videla tuvo como consecuencia una hemorragia que, al cabo de diez horas, lo llevaría a la muerte. Testimonios posteriores señalan que cuando se le comunicó al agonizante doctor Videla la hábil maniobra del comandante Condell que causó la varada de la fragata enemiga y finalmente su rendición, pidió que se le levantara para mirar por la claraboya y dijo: "Muero feliz, pues la causa de Chile sigue incólume, en manos de chilenos que, al igual que yo, están dispuestos a morir en defensa de su patria".

\section{Alma mater lo recuerda}

A modo de homenaje y sólo días después de su deceso, la Escuela de Medicina de la Universidad de Chile entregó a su familia el título profesional que el doctor Videla no pudo recibir por enrolarse en la Armada de Chile. La Sociedad Médica le nombra socio póstumo y le realiza una ceremonia donde se descubriría un óleo con el rostro del héroe. Años más tarde, se traerían sus restos para depositarlo en la cripta de Valparaíso junto a los héroes de Iquique. En Santiago, su Escuela de Medicina le recordaría anualmente en una ceremonia conmemorativa a través de la realización de un medallón conmemorativo, el que se perdería luego del incendio de la escuela en 1948, siendo reguardado el mismo posteriormente en dependencias de Anatomía, donde se conserva hasta el día de hoy (Fig. 2); una réplica se conserva en el Museo Marítimo Nacional, Valparaíso (Vigía, 2016).

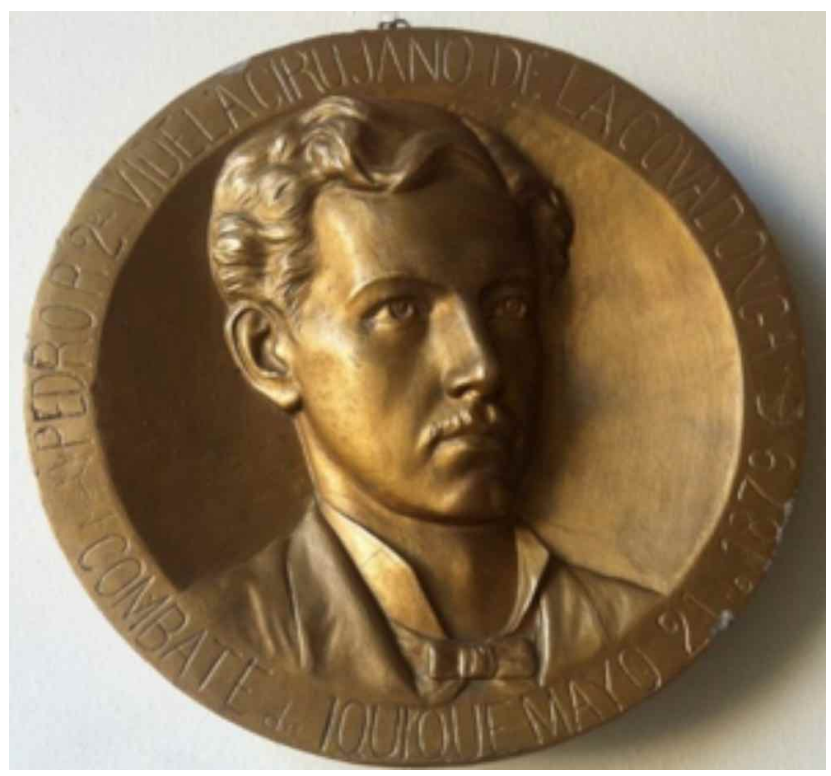

Fig. 2. Medallón conmemorativo del busto del Dr. Pedro Regalado Segundo Videla Órdenes, muerto en el Combate Naval de Iquique el 21 de mayo de 1879.

Ese mismo año, en 1879 Augusto Orrego Luco realizó el "Estudio de las circunvoluciones y surcos del cerebro humano", el que mereció ser premiado por la Universidad de Chile, dando una base objetiva a las "simples especula- 
ciones" de Gall que no eran tan concretas. Era sin duda el trabajo más completo y reconocido a la fecha. Es iniciador de la neuropsiquiatría en Chile y miembro de la Academia de Ciencias de París. Su biografía de Charcot es incorporada como uno de los trabajos extranjeros de homenaje por el gobierno Francés (Laval). Diputado de la República en tres distritos, adversario de Balmaceda; fue Ministro del Interior del Presidente Juan Luis Sanfuentes y posteriormente Ministro de Instrucción del Presidente Federico Errázuriz. Decía el Dr. Charlín sobre Orrego Luco: "Ignoró la pasión del dinero que corrompe a los pobres, ignoró la pasión del poder que corrompe a los ricos.” En vida contó con el más estricto respeto de sus pares, siendo reconocido su aporte por la sociedad de la época en múltiples ceremonias en su honor, ejemplo de ello constituye el homenaje realizado el 2 de Mayo de 1924 con motivo de cumplirse los 50 años de ejercicio profesional, acto en el que el rector de la Universidad don Gregorio Amunátegui Solar entrega al Presidente de la República el diploma y la medalla conmemorativa para ser entregada a Orrego Luco; acuñada en oro, en un lado el emblema de la Universidad y en el otro una leyenda:

"Al varón eminente, que al culto de la belleza y la investigación de la verdad, dio los años dorados de la juventud y los gloriosos de la madurez, al Maestro Orrego Luco, sus colegas médicos, al cumplir los cincuenta años de fecunda vida profesional, este testimonio de alta admiración, dedican”. En Santiago de Chile, el día 2 de Mayo de 1924.

Fue el último delegado, cargo que se mantuvo en la planta de la Escuela de Medicina hasta 1906 proveído por el rector; era el encargado del orden de la escuela, y del que dependían el jefe de trabajos anatómicos, los prosectores, los disectores y los ayudantes de clase. Al fallecer en 1933, no se nombraría reemplazante. Luego de la Guerra del Pacífico algunos médicos regresaron de Europa para incorporarse como médicos militares, acelerándose el desarrollo de la medicina de urgencia. De 1879 a 1881 se graduaron 90 alumnos como licenciados, el número de médicos en Chile sobrepasaba ya los 350 .

En 1881 ingresó Eloíza Diaz Insunza, primera mujer que se titula de médica en 1886, pionera en latinoamérica. $\mathrm{Al}$ año siguiente de su ingreso, entraba la segunda futura médica: Ernestina Pérez Barahona, a la que siguieron otras 6 en ese siglo. Esto trajo dificultades mundanas que hicieron modificar algunas dependencias de las cuales Anatomía no estuvo exenta, con el fin de hacer más llevaderos los estudios.

El viejo edificio de la Escuela de Medicina ubicado en la calle de San Francisco, y las dependencias anatómicas de Morán y Lafargue serían demolidas en 1944 junto con el Hospital San Juan de Dios. En 1885 Santiago tenía 149.395 habitantes; Valparaíso, 100.000 y Chile, 2.500.000. Chile tenía 60 hospitales con cerca de 4.000 camas. La mortalidad intrahospitalaria era de $14 \%$, cifra alta debida en parte a las epidemias. Cuatro años más tarde se fundaría la Pontificia Universidad Católica de Chile, cuya Escuela de Medicina creada posteriormente daría un nuevo impulso al desarrollo de la medicina chilena.

Aumentaron el número de prosectores. Libres ahora de la organización de la enseñanza han podido los prosectores a dedicarse a la labor científica; Entran Carlos Juliet y Raimundo Charlín, magnífico disector, quién ya en 1874 efectuaba preparaciones de vasos linfáticos. Otro de los disectores fue Adolfo Acevedo, exigente en el trato pero merecedor del respeto de sus alumnos por su inflexible justicia e inteligencia. Muy humano con sus pacientes, tuvo el honor de ser propuesto en forma unánime, el 31 de Mayo de 1888 como jefe de trabajos anatómicos. Viene el periodo de agitación política en 1890 y Acevedo, quién siempre se había mantenido lejos del partidismo político, acepta el nombramiento de profesor de clínica quirúrgica; luego de la caída de la dictadura se ve arrastrado por la desgracia al igual que el Dr. Valderrama. El curso de Anatomía dura 2 años. Le sigue a Charlín, el italiano Ambrosio Coste, de origen veneciano, gran disector, artista en su género, con disecciones de gran calidad, algunas presentes aún en el gabinete o Museo igualables sólo a las de Lafargue, era muy alegre contaba Orrego Luco; aventurero, llegó a América a buscar fortuna. Vivió en la Escuela, contando anécdotas traviesas de las universidades italianas, haciendo parodias de los profesores chilenos y bromas que celebraba con interminables carcajadas; desde niño tenía la costumbre de distraer con el canto la monotonía del trabajo, alegrando los obscuros rincones de esta Escuela; muere muy joven en 1882 y le continúa Martín Valenzuela, quién fue designado en 1889 como director del Museo de Anatomía, reemplazando a Marcial Guzmán. A Valenzuela lo reemplazaría a su vez Marcial Rivera. Al ascender a Jefe de Trabajos prácticos, fue designado como disector don Luis A. Solís.

Bajo el gobierno de Balmaceda se aprobó el nuevo plan de estudios en1886, constaba de 6 años, tenía 23 asignaturas y hacía obligatoria la asistencia de los alumnos a los hospitales desde el tercer año, en un ambiente más cómodo y amplio, pero aún con deficiencias en su implementación. Anatomía se enseñaba en los dos primeros años, de 4 horas y media semanales en cada uno de ellos, las clases teóricas se realizaban con pizarrón y tiza.

En abril de 1889 se inaugura el nuevo edificio de la Escuela de Medicina en la Cañadilla, ahora calle Indepen- 
dencia (Fig. 3), depositaria de las anteriores escuelas de medicina (Osorio, 2013). Era un edificio que fue completamente amoblado y ocupado en 1892 de graciosas líneas griegas. Un jardín amplio con dos palmeras en su centro permitía que se destacasen las 6 columnas que se afirmaban sobre un umbral con algunos peldaños. Se ingresaba a un amplio vestíbulo de alto techo con una escalera en forma de "Y" y dos columnas a los lados.

El jefe de trabajos prácticos pasó a ser un empleado especial que dirigía los ejercicios prácticos de anatomía y operaciones, sus ayudantes se llamaban disectores. Las dependencias del pabellón de Anatomía pasaron desde la calle San Francisco a la nueva Escuela de Medicina en 1889; específicamente su anfiteatro al medio del segundo patio de la Escuela. En el pabellón había dos mesas de latón, unas ollas grandes, unas jeringas metálicas de unos $30 \mathrm{~cm}$ de largo por unos 5-6 cm de diámetro, con enchufes de varias dimensiones y cambiables. En esas ollas se fundía manteca con azarcón, polvo de color rojo a base de plomo, y un colorante azul para inyectar arterias y venas respectivamente. $\mathrm{Al}$ fondo de ese patio existía una puerta que comunicaba con el Hospital San Vicente de Paul, de donde traían muchos "recién operados", los que entraban por una puerta orientada al norte, por la calle Panteón en un carretón, el mismo "carretón de los muertos". A ellos se sumaban los cadáveres de la morgue, éstos eran los mejores, jóvenes, porque "son de tipos bien sanos que se matan peleando a puñaladas por el lado de Las Hornillas y por el Matadero". El Chivo Esteban, mozo de medicina operatoria y anatomía (Guzmán, 1964).

Los otros cadáveres, provenientes de los hospitales, eran más bien enjutos, pues había mucha tuberculosis, por lo que tenían un tórax y abdomen estrechos, los músculos delgados y fláccidos. Otros, los muertos de afecciones

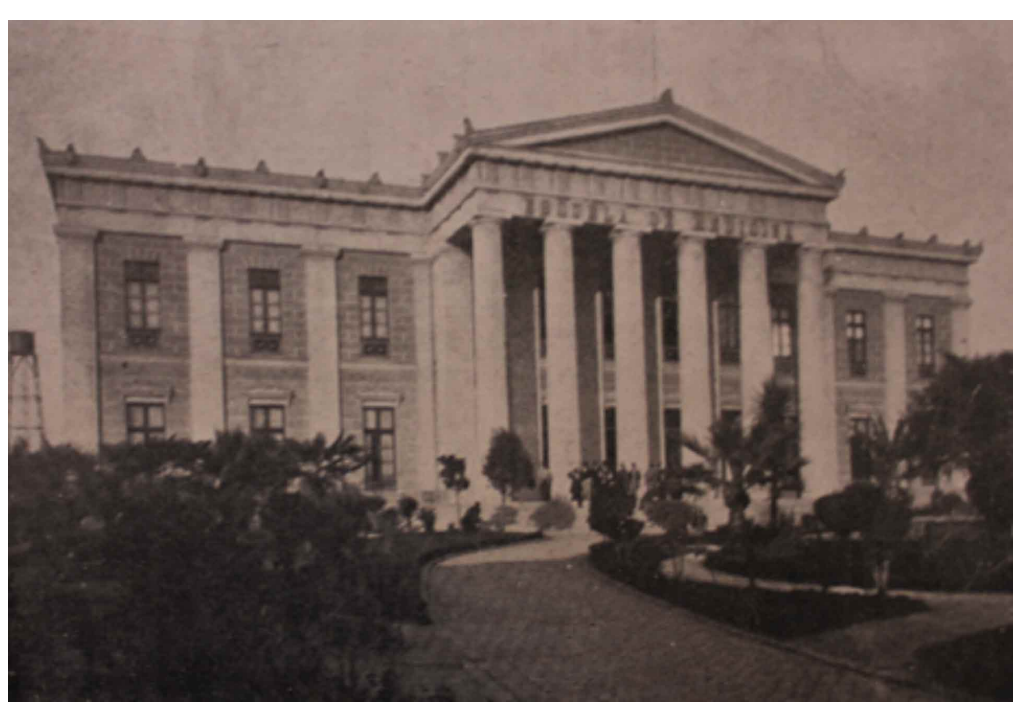

cardiacas o renales aparecían edematosos y añosos. Rostros sin expresión, ojos apagados, inmóviles, semicerrados, mentón caído, bocas abiertas de labios cenicientos con encías desdentadas.

Una afección comprometía de vez en cuando a los estudiantes que practicaban las disecciones, la que era conocida como "la infección cadavérica" (Cárdenas \& Mora) afección que se veía favorecida por la ausencia de uso de guantes, y el uso de desinfectantes como el ácido fénico, gran irritante que producía eczemas y por tanto facilitaba la vía de ingreso de los agentes infecciosos cadavéricos. Hay que recordar que el uso de guantes de goma en Chile fue implementado por los profesores Navarro y Lucas Sierra en 1896, y en anatomía, esta costumbre lo haría a principios del siglo XX.

El internado se inició en 1893 en el ya establecido Hospital San Vicente, ubicado en la misma cuadra. Si bien es cierto que los estudios anatómicos no tomaron un nuevo curso, al menos se realizaban en un ambiente más grato. Profesores y alumnos disponían de un amplio auditorio; las salas de disección erann extensas, incluso para el número de estudiantes, bien iluminadas y abundante ventilación, con sus pisos provistos de planchones de piedra, pero carecían de guardarropía para los alumnos, lavatorios, depósito de cadáveres, refrigeradores, etc. A pesar que el nuevo edificio permitía funcionar en casi todas las clases con el mayor número de ventajas y comodidades posibles, los trabajos de disección no se efectuaban en locales apropiados; se realizaan en el centro mismo del edificio, obviamente sin la aireación adecuadas.

$\mathrm{Al}$ respecto, sobre las condiciones de trabajo, Vargas Salcedo señaló (Vargas, 1925): "Cuantos recuerdos que viven en nuestro espíritu como esculpidos en la piedra. Las disecciones cadavéricas en aquel anfiteatro frío y sin confort donde luchábamos cuerpo a cuerpo con la materia inerte. Los penosos trabajos en el cadáver nos retenían en la Escuela hasta altas horas de la tarde y nos obligaban también a sacrificar la mañana del domingo sin más compañía que la del modesto Salvador. Este pobre y abnegado empleado del anfiteatro nos distraía, nos acompañaba y nos alentaba al trabajo. Hay que trabajar señor, nos decía; todos los caballeros que trabajan anatomía son después grandes médicos...

Fig. 3. Nuevo edificio de la Escuela de Medicina en la Cañadilla, ahora calle Independenciainaugurado en abril de 1889. 

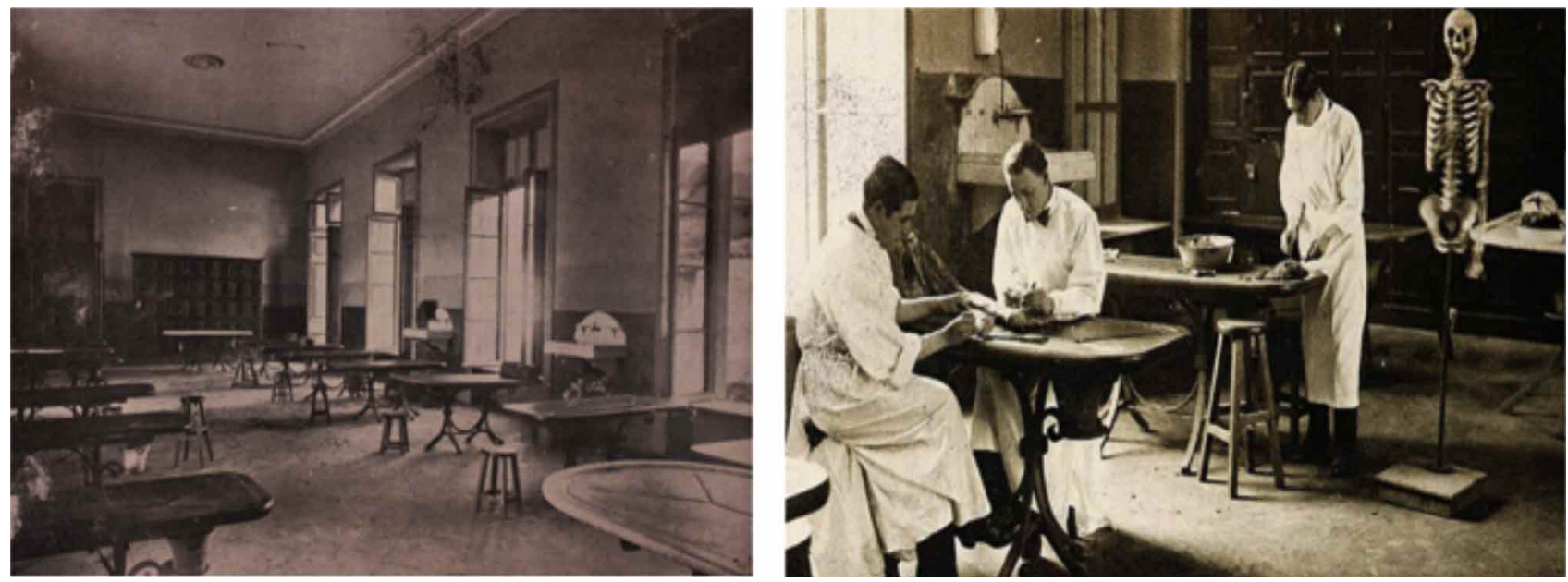

Fig. 4. Anfiteatro de anatomía.

Cuando miro aquellos días desafiando el frío glaciar del anfiteatro, créanme que siento miedo. Pero, todos estos sacrificios nos han dado muchas enseñanzas. El anfiteatro nos ha enseñado a observar a investigar con frialdad, condiciones tan necesarias a todo aspirante al doctorado" (Fig. 4).

Por lo anterior, Alejandro del Río señaló en enero de 1890 a menos de un año de su funcionamiento, que era urgente y de estricta necesidad construir aisladamente de la Escuela pabellones especiales de disección, debido al nuevo aumento en el número de los alumnos. Estarían dadas las bases del actual instituto. En esa fecha, disector de J. J. Aguirre era don Luis A. Solís, y de Orrego Luco don Adolfo Acevedo.

\section{La República Parlamentaria (1891-1925)}

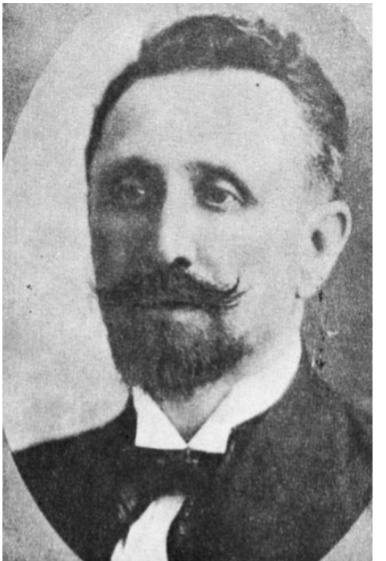

David Benavente. (1863-1949)

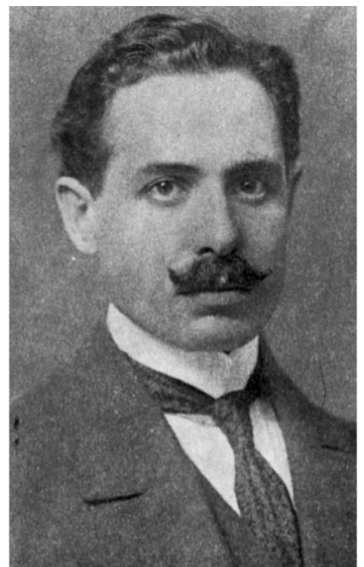

Basilio Muñoz Pal. (1886- 1955)

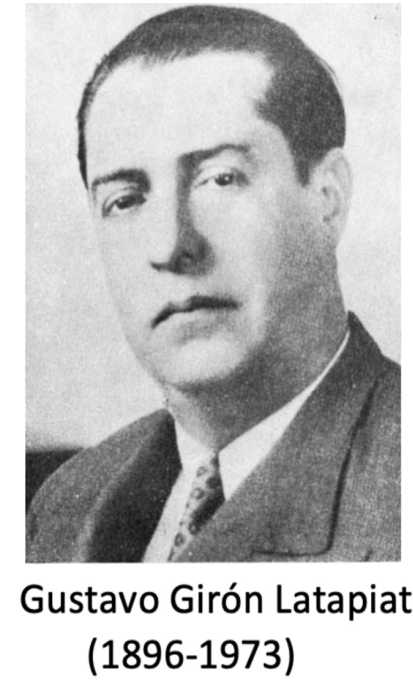

$(1896-1973)$
Fig. 5. Profesores Drs. David Benavente Serrano (1863-1949), Basilio Muñoz Pal (1886-1955) y Gustavo Girón Latapiat (1896-1973).
Al tomar Augusto Orrego Luco la cátedra de enfermedades nerviosas y mentales en 1891 , le sucede don $\mathrm{Da}-$ vid Benavente Serrano (Fig. 5), nacido en Ninhue en 1863. Comisionado por el Gobierno en 1895, fue alumno de Waldayer en anatomía, Duval en Histología y Hertwing en Embriología. Permaneció fuera de Chile hasta el año 1898, siendo reemplazado en ese periodo por don Luis Puyól Medina. A su regreso, ambas cátedras, la de Orrego Luco y la de él mismo de Anatomía quedan en su poder.

Benavente se titula en 1888, Cirujano militar, viaja a Europa en 1895 por tres años, al volver estudia embriología. Es realmente el primer anatomista que efectúa investigaciones en el área: "Contribuciones al Estudio de la Topografía craneoencefálica" en 1894, de hecho fue el primer cirujano que efectuó en forma regular trepanaciones de cráneo en Chile (Grez, 2013). "El aparato hioides y sus funciones" en 1895 y anomalías del colon en 1912 (Cruz-Coke). Era más bien de estatura baja, de mirada dulce y penetrante, silencioso, de palabra serena y armoniosa. Era preciso en el concepto fundamental, no era gran orador y diariamente inspeccionaba a los alumnos en compañía de sus ayudantes Guillermo Ossa y Ricardo Puelma. Reconocido como eximio dibujante, era habitual en dictar sus clases con dibujos realizados sobre los 2 juegos de pizarras de deslizamiento vertical que existía (Fig. 6). Una vez terminados sus dibujos, se alejaba para luego vol- 

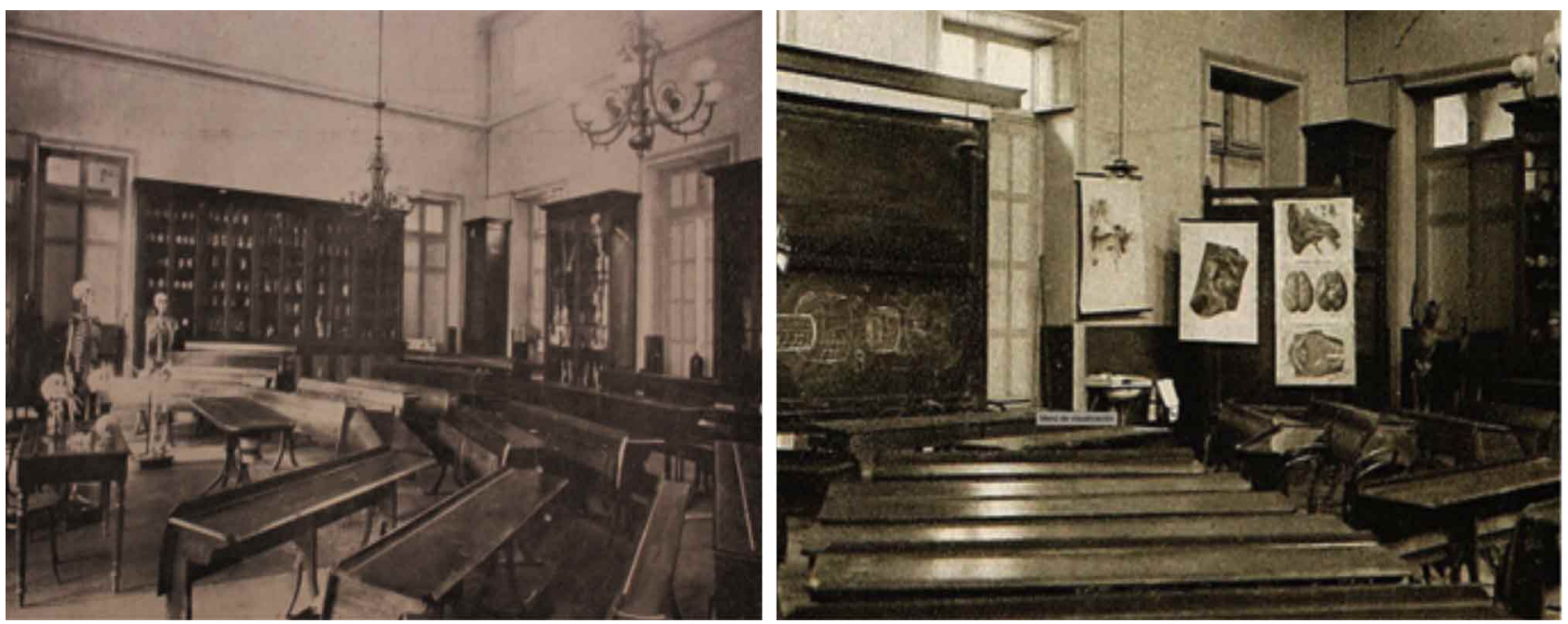

Fig. 6. Sala de clases con dos juegos de pizarras de deslizamiento vertical donde el Prof. Dr. David Benavente Serrano dibujaba.

ver bruscamente a corregirlos y a colorearlos: "El caballero que trabaja aquí, llena estas pizarras de dibujos todo el tiempo. Y por Dios que dibuja bien. Mi compañero anda siempre buscando tiza todo el tiempo, porque el Dr. Benavente gasta muchísima." Elías, mozo de anatomía de la época (Fig. 6).

Luego de la clase, los alumnos iban con sus ayudantes Charlin y Basilio Muñoz Pal a ver los cadáveres.

Posteriormente decidió que se reintegren luego las dos cátedras, renunciando a una de ellas, nombrando la Facultad a Roberto Aguirre Luco, hijo de don Joaquín Aguirre en la otra. Viajaría nuevamente por un año a Europa y le reemplazaría momentáneamente el Dr. Cornelio Guzmán, héroe de la Guerra del Pacífico, sobreviviente del buque "La Esmeralda”. Benavente fallecería en el mes de 16 de Febrero de 1949, en forma silenciosa en su Ninhue natal.

El profesor Roberto Aguirre Luco, se formó en la Universidad de Chile, viajó a Alemania y estudió en Europa al lado de Dieulafoy, Fournier, Ernest von Bergmann, y Farabeuf, entre otros. A su regreso inició su curso de anatomía que pronto alcanzaría renombre, al igual que el que impartía su padre. Fueron más de setenta años de docencia y de calidad impartidos por padre e hijo. En la revolución de 1891 se enrola en el ejército constitucional. Viaja a Argentina en 1900 junto con Alejandro del Río y Mamerto Cádiz a estudiar un brote de peste bubónica. Vuelve al ejército en calidad de cirujano en 1908. En 1923 es elegido decano y se le reelige en 1925. Poseía prodigiosa memoria, dictando las clases con una claridad extrema, se destacó con un brillo extraordinario, siempre rodeado del cariño de sus alumnos mejorando las condiciones de los programas de estudio. Sus clases se iniciaban a las $16 \mathrm{~h}$. apoyándose con láminas ana- tómicas. Por los acontecimientos políticos de 1928, debe dejar la cátedra y reiniciarla en la Universidad Católica. Es ferviente opositor a la dictadura de Ibáñez, periodo en el cual, a través de decretos, se elimina a distinguidos profesores de la Universidad, incluso al mismo Aguirre Luco; rechaza varios nombramientos administrativos como una forma franca de negación. A la caída de Ibáñez, es nombrado Aguirre Luco catedrático de anatomía en la Universidad de Chile, más bien como un acto simbólico de reparación, pues estaba ejerciendo ya en la Facultad de Medicina de la Universidad Católica. Muere en Santiago el 22 de Febrero de 1938. Sus ayudantes eran Pedro Valenzuela Acevedo y Carlos Charlin Correa, este último era hijo de Raimundo Charlín; muy exigente pero apreciado por los alumnos, llegó a ser profesor de Oftalmología, después de duros estudios en Alemania.

El plan de estudios, después de haber sufrido distintas reformas divide ahora las materias de la enseñanza en 6 años:

1er Año: Botánica, Zoología, Química General, Física médica, Anatomía (Prof. David Benavente)

$2^{\circ}$ Año: Anatomía (Prof. Roberto Aguirre Luco, ) se alternaba con David Benavente el curso de 2 años. Embriología, Histología, Fisiología experimental.

3er Año: Química fisiológica, Farmacia, Patología general, Patología médica, Patología quirúrgica, bacteriología.

$4^{\circ}$ Año: Terapéutica, Patología médica, Patología quirúrgica, Medicina operatoria, cirugía.

$5^{\circ}$ Año: Higiene. Anatomía e Histología patológicas, Clínica médica, Clínica quirúrgica, Clínica oftalmológica.

$6^{\circ}$ Año: Clínica obstétrica, Clínica de enfermedades de niños, Clínica médica, Clínica quirúrgica, Medicina legal. 
Luego de estos 6 años, cursarían las especialidades: Otorrinolaringología, Dermatología y Sifilografía, Vías genitourinarias, Enfermedades nerviosas y mentales (Poirier, 1908).

Los médicos de la primera mitad del siglo XIX destacaron también por su formación humanística, el cultivo de las letras y la actividad artística, rasgos que mantendrían muchos médicos chilenos; eran personas influyentes, diputados, senadores, ministros de estado, altas autoridades universitarias. Todo ello favoreció la obtención de recursos materiales para dotar al país de una infraestructura sanitaria ejemplar.

En 1918 se produce el incendio de la Escuela de Farmacia en la calle Zañartu, decidiéndose la creación del Instituto de Anatomía atendiendo al llamado realizado años antes por Alejandro del Río, teniendo el espacio ahora para ello. En noviembre del mismo año, se define un nuevo plan de estudios en la enseñanza de la Anatomía, que se pone en vigencia al año siguiente: se divide el año escolar en semestres, a Anatomía le corresponden cuatro semestres, con 4 1/ 2 horas semanales de clases, aumentando ostensiblemente el número de alumnos, ingresando más de 300, lo que hacía insuficientes los recursos, tanto teóricos como prácticos. Por la cantidad de alumnos, es creada una tercera cátedra, a cargo del doctor Luis Vargas Salcedo, en 1919. Vargas en 1907 había viajado a Alemania estudiando con Waldeyer, Spalteholtz, Perthes y Trendelemburg. A su regreso se integra a la cátedra de Cirugía del Dr. Lucas Sierra, obteniendo posteriormente su título de profesor extraordinario de vías urinarias, además fue designado profesor de cirugía oral de la Escuela dental. Viaja posteriormente a Francia en 1913. Fallecería el 5 de Abril de 1946 a temprana edad considerando su gran capacidad de trabajo.

De esos años, alrededor de 1918 existe una historia que retrata fielmente el ambiente en que estudiaban los alumnos en la Escuela de Medicina en el barrio de Independencia. Como ilustró años atrás el Prof. Dr. Raúl Etcheverry (Etcheverry, 2003), llega a Chile una vez terminada la Primera Guerra Mundial un aventurero francés, Carlos Martel, de cuyo nombre no queda claro su origen o veracidad. (posteriormente el Dr. Alejandro Vásquez Armijo nos señalaría que su verdadero nombre mítico sería el de Juan Martel) (Vásquez, 2008). Se integra al grupo de estudiantes de Medicina, constituyéndose rápidamente en el coordinador de las actividades"extraprogramáticas" donde no eran infrecuentes las visitas al "Quita penas". Años más tarde sus compañeros de parranda encontrarían a don Juan Martel en una de las mesas de disección de Anatomía, frío y pálido. No queriendo abandonarlo a su suerte, a la fosa común por no tener familiares, deciden "secuestrar el cadáver, eviscerarlo y formalinizarlo para su preservación". Le sientan a la cabecera de una mesa como "convidado de piedra" de carne y hueso y activado por una roldana alzan su brazo con una copa al coro unísono de Carlos Martel ; Salud! . El último de los del grupo se lo lleva a su fundo, en Quillota o Quilpué, a una bodega, pero al morir, su viuda decide entregar "una momia" al Museo de Historia Natural, llamando a su director, don Humberto Fuenzalida, (paciente además del Dr. Etcheverry ), quién la aceptaría gustoso para dejarla al lado de "la indiecita del Cerro El Plomo" (Ahora sabemos que en verdad era un indiecito). Tamaña sorpresa al verificar que no era una momia sino un cadáver insepulto, indocumentado, más, para no tener problemas judiciales, forzado acepta a la "momia". En el año 2003, esta momia regresaría desde el Museo de Historia natural al museo de anatomia gracias a un comodato mediado por la dirección de archivos y museos (Valenzuela, 2012).

Luego del año 1918, y debido al aumento de los alumnos, 300 postulantes para primer año, el mejoramiento de la calidad de preparación de preparados en la docencia y nuevas técnicas de conservación fue necesario no sólo ampliar el edificio sino también reconstruirlo, construyéndose un nuevo pabellón de anatomía, que sería el futuro Instituto de Anatomía. Santiago tenía 507.000 habitantes. Gracias a las gestiones del Decano, el Dr. Amunategui y el profesor Vargas Salcedo, se obtuvieron los recursos por parte de la Dirección de Obras Públicas, cantidad que alcanzó a los \$186,000 (Memoria del Director de la Escuela de Medicina 1921, 1922a) y el 16 de junio de 1920 queda aprobado su reglamento. Con ese dinero continúa y se concluye la edificación, inaugurándose el 4 de Mayo de 1922 por el Presidente de la República, acompañado por el ministro de Interior Armando Jaramillo e Instrucción Sr. Guarello. En esa ocasión, el Decano agradece la construcción de este Instituto a las autoridades, destacando la importancia de contar con un recinto de estas características para los estudios anatómicos, así como las condiciones higiénicas en que se desarrollarían los mismos.

Se denominó a partir de ese momento Instituto de Anatomía, quedando sometido a la Facultad de Medicina y a la Escuela de Medicina, siendo dirigido por un Inspector del Instituto y del Museo Anatómico, médico titulado de la Universidad de Chile, con la intención de velar por siempre su patrimonio. Su entrada sería por la calle del Panteón, $\mathrm{n}^{\circ}$ 1126 (desde 1931 se llama Profesor Alberto Zañartu Campino, en homenaje a un pedagogo, uno de los muertos por la dictadura de Ibánez, muerto el 25 de Julio de ese año, cerca del pensionado del Hospital San Vicente de Paul). Son los profesores quienes quedan a cargo de organizar y disponer del funcionamiento del Museo. El Inspector debía velar por el orden y aseo del Museo, poner a disposición de 
los profesores el material docente adecuado, hacer preparaciones anatómicas, adquirir aquellas que no se pudiesen conseguir en el Museo, obras, publicaciones periódicas, aparatos, instrumentos, formar el Museo Anatómico, etc. Se designó un Comité de Vigilancia, formado por el entonces director de la Escuela, Dr. Edmundo Jaramillo, el profesor de anatomía Dr. Roberto Aguirre Luco (quién sería decano al año siguiente) y su jefe de trabajo práctico ,el Dr. Gustavo Jirón; se inauguró el 4 de Mayo de 1922 como homenaje natural a José Joaquín Aguirre, al cumplirse 100 años de su nacimiento el 22 de Mayo de 1922, asistieron el Ministro del Interior Sr. Armando Jaramillo y de Instrucción Sr. Guarello, la casi totalidad de los académicos de la Facultad, algunos médicos de provincia y numerosos alumnos. Su "bronce", aludiendo al busto de José Joaquín Aguirre "en este auditorio, es un buen augurio. Don José Joaquín Aguirre es el patrono del Instituto de Anatomía “, palabras del decano de Medicina don Gregorio Amunategui, durante la ceremonia de inauguración. A continuación el Prof. Augusto Orrego Luco dicta una conferencia sobre el profesor J. J. Aguirre, especialmente sobre los estudios anatómicos en la vieja Escuela de San Francisco (Instituto de Anatomía, 1922c).

Las dos salas de Anatomía, que en la Escuela ocupaban los servicios de disección, se transformaron en una, en un cómodo auditorio para la clase de Fisiología Experimental del profesor Muhm y salas anexas para los trabajos prácticos, la otra, también espaciosa para los trabajos de laboratorios para Química General y Biología del profesor García Valenzuela (Memoria del Director de la Escuela de Medicina, 1924).

Más adelante, alrededor de 1948, tanto por el constante aumento de los estudiantes como por la necesidad de incorporar nuevas técnicas en la conservación cadavérica y piezas para la docencia, se reconstruye el Instituto, manteniéndose sólo el auditorio; en ese momento se modificó éste también, clausurándose la puerta central, dejando o agregando dos entradas por la planta del primer piso y agregándose un pasillo que lo circundaba ampliamente por detrás, con 3 entradas para los alumnos, una central y dos laterales, construyéndose una pieza en el pasillo posterior para el equipo de proyección. Se mantuvo el sistema de engranaje central que hacía subir una camilla con el cadáver luego de dictarse la clase; este mecanismo quedaría oculto para las generaciones futuras, incluso de docentes, al cubrirse con alfombra este lugar, para luego desmantelarse definitivamente.

En 1920 se integra una nueva cátedra, la cuarta, a cargo del prof. Don Basilio Muñoz Pal. (Fig. 5). Fue ayudante del Prof. Benavente desde 1907, su jefe de trabajos prácticos, su sucesor . En 1913 viajó a Berlín, asistió a las clases de anatomía descriptiva de Waldayer, Tauber y Kopasch. El año 1914, y mientras estaba en Europa, se le designó como ayudante de la cátedra de Bier mientras los cirujanos propietarios estaban en el campo de batalla. Era la Primera Guerra Mundial. "Restos de este viaje se encuentran actualmente bajo el Auditorio de Anatomía; envueltos en diarios alemanes de la época están parte de las láminas anatómicas realizadas en la cátedra de Muñoz Pal. Trae desde Alemania parte de las telas en que se pintaron dichos cuadros, presentes en ese recinto y de los cuales no existían evidencias sino desde el año 2003"

\section{Láminas anatómicas}

Las láminas anatómicas estaban dispuestas en 13 áreas temáticas. Son más de 470 cuadros que en la actualidad se conservan bajo el anfiteatro (Cárdenas et al., 2017). Se encuentran en un mueble de madera estilo Cruz-Montt construido especialmente para guardarlos y protegerlos; de forma circular sigue la curva del auditorio. Presenta 4 pares de puertas dobles enmarcadas con vidrio. Las láminas tenían un ancho de alrededor de 1 metro, y su largo en la mayoría de ellos un promedio de 1,5 metros. Los cuadros disponían de un cordel para colgarlos, el caul se anudaba en listones negros de madera dispuestos en su parte superior e inferior y torneados en sus extremos.

Sobre los autores puedo señalar que no sólo alumnos participaron en la realización de estas láminas, también los futuros docentes como Enrique Solervicens y Luis Vargas Salcedo, de quién existen trabajos dibujados en 1903 cuando aún eran alumnos; hay que recordar que Vargas Salcedo se recibió en 1905, haciéndose cargo de la cátedra en 1919. Prueba de la calidad artística de Vargas Salcedo no sólo son sus láminas, sino también, una alusión que hace al respecto el profesor Muñoz Pal al terminar la lección inaugural de la nueva Cátedra de Anatomía, en 1922:

"y por último, que Vargas haga Anatomía, con su vena de artista, acostumbrado desde niño a manejar el lápiz y el pincel, como lo atestiguan tantas láminas de nuestra colección , hechas por él, es justo y no sorprende a nadie."

Hubo algunos estudiantes que no se dedicaron a la medicina finalmente, sino más bien a las artes, como el caso de Juan Frutos Martrat, quién inicia sus estudios de Medicina pero no los concluye, se retira y sigue su afición artística, ganando premios en Europa, quedando sus obras a las generaciones futuras, siendo autor de las dos megaláminas que decoran el frontis del Anfiteatro de Anatomía de la Universidad de Chile, y que es posible apreciar hasta hoy; de aproximadamente 1 metro de ancho y 3 metros de alto, de- 
coran el frontis del Anfiteatro, mostrando ambos un corte sagital de un cadáver de sexo masculino, los que aún son posible de apreciar. La fuente de estas dos obras, provendrían del libro Atlas of Human Anatomy and Surgery (18311854) J. M. Bourgery.

Jenaro Cecchi A. otro connotado autor por su prolífica y bella obra se recibiría en 1922, en la promoción junto a Sótero del Río y Alfredo Yazigi (Médicos titulados en 1922, tomo LII, 1922b). Otros autores serían connotados artistas posteriormente, como ocurre con Pedro Luna Pérez, quién pertenece a una cofradía denominada Los Caimanes, en la que se reúnen estudiantes, artistas y pintores de la época. El, junto a Pedro Lira y Camilo Mori, pertenecerían al grupo de la "Generación del trece" o "Heróica Capitania" denominación dada por Pablo Neruda a este grupo de artistas por presentar sus obras en conjunto ese año en una exposición en el Bellas Artes. (Zamorano, 2008). Sin embargo la mayoría de las láminas derivaría de los libros de Leo Testut; éste y otros libros serían donados a la biblioteca del museo por el prof. Girón. Esta metodología de enseñanza a través de láminas sería una tendencia adoptada por varios países tanto en Europa como en américa.

En 1930 Muñoz Pal vuelve a Alemania a seguir perfeccionándose en los estudios de Anatomía descriptiva. A su regreso, la Rectoría le solicita un texto de Anatomía, el que inicia en 1949, dándole término el $1^{\circ}$ de Enero de 1955. Debido al alto costo de las impresiones de las láminas, no se concretó su publicación. Aún está inédito y estaría en poder de su familia. Al retirarse en 1947, se le designa profesor extraordinario de anatomía.

En estos 25 primeros años del siglo 20 las clases se dictaban tres veces en la semana, de una a una hora y media de duración cada, una ciñéndose estrictamente la materia a la Anatomía Descriptiva de Testut, o de Testut Latarjet, que constaba de 4 voluminosos tomos, ó el "Testut chico", especie de compendio, sin ilustraciones. Se acompañaba además la clase teórica con dibujos efectuados por el profesor, como sucede con Benavente o láminas copiadas del mismo texto por alumnos, para posteriormente mostrar las preparaciones en el cadáver o piezas del Museo sobre la materia que el profesor acababa de dictar.

En cuanto a las disecciones obligatorias, exigidas en número de 40 en primer año y otras 40 en segundo, constituían un gran desafío para el estudiante, pues al problema en la obtención del material cadavérico, había que agregar el numeroso contingente de alumnos en espera para ello. Por eso existió el sistema que se conoció con el nombre de "marca libre", donde el primer alumno que llegaba marcaba en el cadáver con lápiz tinta lo que deseaba disecar, respetándose los turnos con una caballerosidad admirable según nos cuenta Enrique Laval. Era necesario sin embargo hacer fila desde la una de la madrugada, a pesar que la Escuela se abría a las 7, no importando lluvia frío u otra inclemencia del clima. Muchas veces y luego de la larga espera, durante la madrugada, llegaba el mozo de operatoria, y diciendo: "este cabro es mío" dejaba en espera para otro día a los sacrificados estudiantes. Mucho tiempo después se abandonaría este sistema.

En el año de 1919 el doctor Gustavo Girón Latapiat (Fig. 5) se recibía de médico, tres años más tarde obtuvo su título de profesor extraordinario de anatomía topográfica y tres años después, sucede a Vargas Salcedo en anatomía Descriptiva, cuando éste es promovido a la cátedra de clínica quirúrgica. Antes, sería ayudante de Orrego Luco. Realizó múltiples estudios anatómicos basados en nuestra propia anatomía chilena. Diría:"La Anatomía del hombre blanco no es la anatomía de la humanidad entera" como señaló años antes el profesor Loth de Varsovia (Jirón, 1946). Presentó una tesis: "Algunas consideraciones sobre la anatomía descriptiva y topográfica del bazo", uno de los puntos de partida para iniciar los trabajos anatómicos de nuestra anatomía chilena. Así, Solervicens en 1942 pondría en relieve la diferencia observada en el sistema simpático abdominal, sobre el plexo solar ("masa solar") en 1946 (Solervicens, 1946). Henckel y Skews estudió en 1953 el peso del bazo, corazón, hígado y pulmones; Moisés López lo haría en relación al drenaje de los vasos linfáticos, donde Harnecker más adelante describiría con mayor exactitud, destacando sus diferencias en relación a la anatomía tradicional anglosajona. Es más, a partir de estos trabajos, los anatomistas del Cono Sur inician también sus estudios anatómicos regionales. Incluso H. Rouvière hizo mención de Jirón sobre diferencias en cisuras pulmonares y vena ácigos. Girón dirige el Instituto de Anatomía, integrando su Comisión de Vigilancia, fue su motor para convertir en realidad el sueño por mucho postergado, creando los departamentos de diafanización, momificación y corrosión, además de una sección de anatomía plástica, hasta hace 40 años atrás la única en Sudamérica, que permitió copiar con fidelidad cuadros anatómicos tomados del cadáver; tallados primero en cera, se reproducían luego en látex o yeso. Permitiendo por ello conservar las piezas del Museo facilitando la investigación. Fundó la anatomía radiológica, impartiéndola en los trabajos prácticos. Siempre inculcó el más severo respeto al cadáver humano fuente primaria e imprescindible en la enseñanza de la medicina. La sección de diafanización, corrosión y momificación estaría a cargo del especialista Jurgen Baumann hasta 1962 (Laval).

Dio también una importancia especial al estudio de la anatomía fetal y del recién nacido, donde la Dra. Erna Mahn diseca más de 800 fetos en una tesis denominada "Anatomía fetal, la cavidad abdominopelviana”(Mahn, 
1933). Su hijo Arturo Girón junto a José Torres presentó "Algunas consideraciones en la anatomía del feto y recién nacido". Su obra más notable fue el Museo de Teratología, uno de los más completos del mundo en su época, (Cancino, 1988) con más de trescientos fetos, que comenzó con la llegada de un feto de sexo femenino, una "sirena" (feto unido en sus miembros inferiores que recuerda a aquel ser mitológico ) desde Lebu. Desde todas las maternidades del país enviaban estos fetos para su posterior estudio, los que incluso son objeto de investigación hasta la actualidad; así es posible apreciar fetos con hidrocefalia, gemelos fusionados, cíclopes, seres amorfos, etc. En esos años llegaría a Anatomía un persona que conoceríamos como "Correíta", quién fue solicitado al igual que su padre por el Profesor Girón para que trabajara en Anatomía quedándose hasta ya avanzada edad. Vendría trasladado desde la Escuela Dental. Su nombre en verdad era Fortunato Gavilán y nos señalaría que la mayoría de los fetos llegaron desde la maternidad del Hospital Salvador y del hospital J. J. Aguirre, siendo el custodio de este espacio y del museo hasta su muerte.

Girón funda el 27 de Diciembre de 1933 los Archivos Chilenos de Morfología, siendo su Director. En el $\mathrm{n}^{\circ} 1$ del Tomo 1 el Dr. Nelson Flores, ayudante de anatomía desde 1923 cuando era aún estudiante, y ahora como su Secretario General, hizo un relato de la Historia de la Anatomía en Chile (Flores). Más tarde Flores sería Jefe de trabajos prácticos y profesor de Anatomía descriptiva. Durante 10 años, entre 1934 y 1944 se desempeñaró como Jefe Administrativo del Instituto de Anatomía Normal. Estos Archivos serían el órgano oficial de la Sociedad de Anatomía Normal y Patológica de Chile (Rodríguez \& Cárdenas, 2017) la que fue fundada en dependencias de la Sociedad Médica de Chile en Santiago el 12 de Agosto de 1938. Fue Senador por Santiago en los años 1941 a 1949. Presidente de la Asociación Médica de Chile y Presidente del Colegio Médico de Chile. Pedro Castillo Yañez ingresó en 1948 como ayudante ad-honorem para luego, en 1958 ser jefe de trabajos prácticos. Gustavo Girón jubiló en 1962, logrando en más de 40 años, formar una biblioteca particular de Anatomía, considerada por los entendidos como una de las más valiosas y completas del Continente. Fue condecorado con la medalla de oro por su destacada labor como médico por el colegio médico en 1971. Falleció el 29 de Marzo de 1973.

CÁRDENAS, V. J. History of Anatomy in Chile Part II. The alma mater. Int. J. Morphol., 38(4):1074-1089, 2020.

SUMMARY: After 200 years of informal anatomical science education in Chile, the anatomy studies program of the Spanish Royal University of San Felipe (1758), is passed on to Chile's National Institute in the year 1833. Subsequently in 1842, the studies program is transferred to the current Universidad de Chile, and following the percepts of Spanish Medicine, records indicate the development of this discipline was carried out under wretched conditions, that included serious risks associated with infections and injuries during practices. There is also reference to the origin of the first corpses used in education between the year 1842, when the University was established, and 1920, the year in which the Institute of Anatomy moved to its present location. During this initial period, our professors were of French origin, which was followed by German influence, and later featured North American influence. Therefore, the objective of this work is to describe the continuity of Human Anatomy teachings, currently reliant on the Universidad de Chile. This being the oldest educational institution in the country, it constitutes the origin and alma mater of many anatomists, who will be responsible for the teaching and instruction of anatomy in the rest of the country.

KEY WORDS: Anatomy; History of Anatomy; University de Chile.

\section{REFERENCIAS BIBLIOGRÁFICAS}

Boletín de las Leyes y de las Órdenes y Decretos del Gobierno. Valparaíso, Imprenta del Mercurio, 1846. pp.357-8.

Cancino, A. E. 1er Coloquio Museos de la Universidad de Chile. Santiago de Chile, Universidad de Chile, 1988.

Cárdenas, J. \& Mora, D. La infección cadavérica en Chile, muerte en el anfiteatro anatómico. Rev. Chil. Infectol., 35(5):595-600, 2018.

Cárdenas, V. J. L. History of anatomy in Chile. The Beginnings. Int. J. Morphol., 35(3):958-69, 2017.

Cárdenas, V. J. L. The anatomical statue of Dr. Auzoux. First anatomical model of teaching purposes in Chile. Int. J. Morphol., 33(1):393-9, 2015.

Cárdenas, V. J. L.; Dinator, E. M. \& Madariaga, L. J. Description of the anatomical plates of the Universidad de Chile, a National Monument. Int. J. Morphol., 35(2):711-8, 2017.

Chanal, N. P. J. L'Anatomie Clástique de Louis Auzoux, une Entreprise au XIX ème Siècle. Tesis Doctorado. Maisons-Alfort, École Nationale Vétérinaire d’Alfort, 2014. pp.69. Disponible en: http://theses.vetalfort.fr/telecharger.php?id=1742

Cruz-Coke, M. R. Historia de la Medicina Chilena. Santiago de Chile, Editorial Andrés Bello, 1995.

Etcheverry, R. Generación del '34 ¡Presente!, Huella y Presencia. Santiago de Chile, Amanda Fuller, 2003. pp.65.

Ferrer, P. L. Historia General de la Medicina en Chile: (Documentos Inéditos, Biografías y Bibliografías): Desde el Descubrimiento y Conquista de Chile, en 1535, hasta nuestros días. Talca, Imprenta Talca J. Martín Garrido, 1904.

Flores, N. Historia de la Anatomía en Chile. Arch. Chil. Morfol., 1(1), 1933.

Grez, I. M. Dr. David Benavente Sepúlveda. La otra biografía. Rev. Chil. Cir., 65(1):73-6, 2013.

Guzmán, L. Mis recuerdos de estudiante. An. Chil. Hist. Med., 1(6):9-169, 1964.

Instituto de Anatomía. Rev. Méd. Chile, 1922c. pp.456.

Jirón, G. L. Los cuadros anatómicos clásicos y sus variaciones. Arch. Chil. Morfol., 6:47-51, 1946.

Laval, M. E. Evolución de la enseñanza de la anatomía en Chile. An. Chil. Hist. Med., 6(2):7-75, 1964.

Mahn, H. E. Memoria para Obtención de Título Médico Cirujano Universidad de Chile, Cátedra Gustavo Jirón. Santiago de Chile, Universidad de Chile, 1933. 
Médicos titulados en 1922, tomo LII. Rev. Méd. Chile, 1922b. pp.165.

Memoria del Director de la Escuela de Medicina 1921. Rev. Méd. Chile, 1922a. pp.324.

Memoria del Director de la Escuela de Medicina. Tomo LII. Rev. Méd. Chile, 1924. pp.714.

Orrego, L. A. Recuerdos de la Escuela. Santiago de Chile, Imprenta Universitaria, 1924.

Osorio, C. Historia de la Escuela de Medicina de la Cañadilla. Rev. Méd. Chile, 141(11):1486-8, 2013.

Poirier, E. Chile en 1908. $5^{\mathrm{a}}$ ed. Barcelona, Santiago, 1908. pp.170-4, 179.

Rabí, M. La formación de médicos y cirujanos durante los siglos XVI a XIX: Las Escuelas Prácticas de Medicina y Cirugía en el Perú. An. Fac. Med., 67(2):173-83, 2006.

Rodríguez, T. A. \& Cárdenas, V. J. The origins of the Society of Normal and Pathological Anatomy of Chile. Int. J. Morphol., 35(2):751-5, 2017.

Sanidad Naval entregó importante donación al Museo Marítimo Nacional. Vigía, (371):33-5, 2016.

Semir, M. Apuntes para la Historia de la Enseñanza en Chile. Santiago de Chile, Memoria Incorporación a la Facultad de Medicina. Anales de la Universidad de Chile, 1860. pp.746-7.

Silva, J.; Araya. C.; Cárdenas, J.; Salcedo, A.; Mansilla, B.; Hernández, A.; Rodríguez, P.; Salazar, M.; Caracuel, R. \& Espinoza, M. Anatomical Bibliography Used in the Training of Physicians in Chile Between 1758 and 1840. Int. J. Morphol., 37(3):938-56, 2019.

Solervicens, E. Los cuadros clásicos y sus variaciones. Arch. Chil. Morfol., 6:52-9, 1946.

Vaisse, E. Biografía de Augusto Orrego Luco. An. Chil. Hist. Med., 3:381, 1961.

Valenzuela, L. C. Momia de Carlos Martel Vuelve a su Casa. Santiago de Chile, Universidad de Chile, 2012. Disponible en: https://www.uchile.cl/ noticias/81767/momia-de-carlos-martel-vuelve-a-su-casa

Vargas, S. H. Lección inaugural de Clínica Quirúrgica. Rev. Méd. Chil., 1925.

\author{
Dirección para correspondencia: \\ Dr. Julio Cárdenas Valenzuela \\ Prof. Asociado \\ Departamento de Anatomía y Medicina Legal \\ Director Museo de Anatomia \\ Facultad de Medicina \\ Universidad de Chile \\ Santiago \\ CHILE
}

Recibido: 28-06-2019

Aceptado: 16-01-2020

Email: jcardenasvalenzuela@gmail.com 